\title{
Fascismo e Discurso Capitalista: um objeto sintético
}

\section{Fascism and Capitalist Discourse: a synthetic object}

Marcos Vinicius Brunhari*1

Este artigo parte de duas afirmações de Lacan a respeito do fascismo e se orienta pelo questionamento sobre o valor de objeto dos elementos falaciosos, oferecidos como promotores de coesão na multidão fascista, que se propagam e são consumidos de maneira veloz. Esses objetos permitem um exame histórico do ideal fascista e uma articulação às proposições lacanianas sobre o Discurso Capitalista. São retomadas as contribuições freudianas acerca da manutenção libidinal das massas, bem como a incidência delas sobre o pensamento de Reich e de Adorno em suas asserções sobre o fascismo. Justapor os elementos do Discurso Capitalista em um ordenamento que conjuga o líder, o saber demagógico, o objeto sintético forjado e o sujeito em sua recusa à dimensão da falta é o que permite articular esse discurso sem laço social ao que se destaca a respeito da coesão da multidão fascista.

Palavras-chave: Psicanálise, capitalismo, fascismo, discursos

${ }^{* 1}$ Universidade do Estado do Rio de Janeiro - UERJ (Rio de Janeiro, RJ, Brasil). 
O obscurantismo como prática política é atualidade de um processo que não é desatrelado da especial ênfase às implicações sociais das mídias tradicionais e da propagação de ideais preponderantemente apregoados às classes dominantes. No interim dessa publicidade, assistimos à emergência expressiva, a partir também das novas mídias sociais em sua capacidade de divulgação ostensiva, de coordenadas falaciosas que, geridas por um maquinário francamente arraigado de ódio, se ocupam da derivação e incitam movimentos massificados. Esses movimentos que se deflagram por vias digitais, alcançam o estrato social em forma, por exemplo, de informações sobre distribuição, em escolas, de itens eróticos para crianças; de carreatas contra o isolamento social como medida preventiva no contexto da pandemia de COVID-19; de manifestações contrárias às instituições e ordem democrática; e na difusão da banalização do extermínio negro, indígena e LGBTQIA+ no Brasil. Salientamos nisso a marca de uma propulsão ao movimento que então se depreende da divulgação de conteúdos de ódio, predominantemente pelas redes sociais, em uma dinâmica que confere a essa relação um caráter de consumo.

Esses conteúdos são fabricados em uma escala para fins de consumo. Isso nos leva a questionar o valor de objeto desses elementos falaciosos que se propagam de maneira veloz e que se oferecem como promotores de coesão entre as massas. Ter como questão o objeto de consumo que gera coesão entre os membros da multidão leva em consideração o aspecto histórico do movimento fascista (Paxton, 2007), que tem na propaganda seu registro de eficácia, e a proposição lacaniana de um Discurso Capitalista (Lacan, 1972/1978) com a peculiar sagacidade da implicação do objeto sobre o sujeito. $\mathrm{Na}$ sustentação dessa 


\section{ARTIGOS}

articulação, recorreremos às contribuições de Freud (1921/1996a) relativas à coesão libidinal das multidões, aos desdobramentos de Wilhelm Reich (1933/1988) sobre a família autoritária e o evitamento do sexual, bem como das precisões de Theodor W. Adorno (1951/2015) a respeito da demagogia e do caráter sintético da propaganda fascista. Assim, partimos de duas afirmações pontuais de Lacan $(1964 / 1998 ; 1971 / 2009)$ sobre o fascismo que nos permitem empreender a problemática aqui introduzida.

A primeira afirmação se localiza no Seminário. Livro 11. Os quatro conceitos fundamentais da psicanálise (1964/1998), e nela Lacan retoma a proposta freudiana (1921/1996a) a respeito da comparação entre o estado de paixão e a hipnose como tendo a identificação com processo fundamental. Ao estabelecer a identificação como crucial entre o apaixonamento e a hipnose, Freud lançou uma proposta sobre a formação da fascinação coletiva, a qual é retomada por Lacan (1964/1998) como uma "realidade ascendente" (p. 257) na segunda década do século XX, momento em que Freud a delineou. Adiante retomaremos com detalhes a proposta freudiana sobre a fascinação coletiva e a possibilidade de articulá-la ao fascismo; por ora, apenas consideremos que Lacan faz emergir essa contribuição ao afirmar que há uma peculiaridade que se evidencia pela sobreposição entre o objeto $a$ e o ideal do eu. Elevar o objeto $a$ ao lugar do ideal do eu é o que viabiliza a identificação da massa e a constituição de um líder. Segundo Lacan (1964/1998), "é dessa idealização que o analista tem que tombar para ser o suporte do a" (p. 258), afirmação que coloca o analista em contraposição ao líder, o qual se sustenta libidinalmente pela identificação fomentada entre os membros da massa.

Ainda nessa primeira referência que aqui destacamos, Lacan (1964/ 1998) menciona a atualidade da vinculação entre o objeto $a$ e a ciência. Especificamente quanto aos mass-media, canais de comunicação em massa oriundos dos progressos da tecnociência, que difundem a informação de maneira generalizada tendo como veículos objetos que invadem o cotidiano das sociedades. São destacados os objetos voz e olhar como primordiais enquanto instrumentos produzidos pela ciência e que servem a certa forma de regulação da vida. Em associação a esses objetos forjados pelos progressos da ciência, Lacan aponta algo que, segundo ele, está mascarado na crítica da história e se presentifica como um "drama nazista" (1964/1998, p. 259). Esse drama tem uma dada atualidade notada pelo psicanalista e é o que torna presente formas de holocausto. Ainda segundo o autor:

Afirmo que nenhum sentido da história, fundado nas premissas hegelianomarxistas, é capaz de dar conta da ressurgência, pela qual se verifica que a 
oferenda, a deuses obscuros, de um objeto de sacrifícios, é algo a que poucos sujeitos podem deixar de sucumbir, numa captura monstruosa. (p. 259)

Ao pluralizar a forma de holocausto entende-se que o objeto de sacrifício também pode ser diversificado. Essa oferenda aos deuses obscuros faz do sujeito um objeto em uma captura que pode ser explicada pela ignorância e pela indiferença (1964/1998, p. 259). Ter o sujeito sob tal estatuto de sacrifício traz um mistério sobre o objeto que, nesse drama, testemunha a imponência desse deus obscuro como um Outro desejante. Embora seja importante interrogar o que define o objeto a ser sacrificado, sobre a ausência de hegemonia e como sua constituição faz jus ao campo da tecnociência, enxergamos na limitação da premissa hegeliana-marxista, acima aferida, algo digno de nota. Trata-se de uma crítica ao pensamento que infere que a ressurgência, na história, do horror como política seja atribuível ao insucesso do capitalismo. Não é melhor evidenciada a proposta do autor a respeito dessa discussão, mas sua contrariedade às premissas sobre os limites do sistema capitalista nos permite interrogar sobre a presença de um ilimitado próprio ao capitalismo como característica cabal no retorno da oferta de sacrifícios aos deuses obscuros.

A segunda referência ao fascismo que destacamos no ensino de Lacan se localiza no $O$ seminário. Livro 18. De um discurso que não fosse semblante (1971/2009). A relação entre o objeto $a$ e o ideal do eu é mais uma vez resgatada, mas agora no nível do discurso: "Num discurso, aquilo que se dirige ao Outro como um Tu faz surgir a identificação com algo que podemos chamar ídolo humano" (p. 28). Depreende-se dessa asserção que o fascínio e a idealização se edificam sobre um Tu que se apresenta imaginariamente como passível de investimento libidinal. Desde o início da década de 1960, essa identificação imaginária encontra no ensino de Lacan um além da superfície projetada do $\mathrm{Eu}, i(a)$, revelando a dimensão real relativa ao objeto a. É a partir desse objeto, como mais gozar, que Lacan (1971/2009) faz interpelar o processo de identificação que promove o líder e certo discurso que se ocupa de particular maneira da ordenação do gozo, o discurso do capitalista:

Em todo discurso que recorre ao $\mathrm{Tu}$, alguma coisa incita a uma identificação camuflada, secreta, que só pode ser a identificação com um objeto enigmático que pode não ser absolutamente nada, o pequeníssimo mais-de-gozar de Hitler, que talvez não passe de seu bigode. Foi o quanto bastou para cristalizar pessoas que não tinham nada de místico, que eram o que há de mais engajado no processo do discurso do capitalista, com o que isso comporta de questionamento do mais-de-gozar sob a forma de mais-valia. A questão era saber se, 


\section{ARTIGOS}

num certo nível, as pessoas ainda teriam seu pedacinho, e foi isso mesmo que bastou para provocar esse efeito de identificação. (p. 28)

A preponderância imaginária em um processo identificatório indica que um a mais de gozo se faz valer a partir de um objeto enigmático. Esse objeto, que pode ser um pequeno detalhe ou que esteja além da imagem, cristalizou pela identificação aqueles que nisso buscaram garantir a sustentação de um líder compatível aos ideais almejados pela coletividade em dado momento histórico. Não em uma vertente mística, mas sim em uma economia orientada pelo mais-valor marxista, é que a identificação como esteio do fascínio tem no Discurso do Capitalista, como procuraremos sustentar ao longo deste artigo, uma forma de respaldo a partir da qual um objeto enigmático se torna promotor da coesão de massas em um processo de instituição no qual um líder assume determinada regência sobre o sujeito que é implicado por esse objeto forjado por um saber tecnológico.

\section{Sobre o fascismo: a história do presente}

Extraímos de Robert Paxton (2007) o entendimento de fascismo como uma inovação política e causa dos maiores sofrimentos sociais do século XX. Fascismo é uma expressão originada, enquanto termo, do uso feito por Mussolini para descrever o estado de ânimo de soldados nacionalistas que retornavam da Primeira Guerra Mundial (1914-1918), de certo grupo de intelectuais e de apoiadores da guerra que se organizavam em torno do então novo líder italiano. O termo fascismo é assim oficialmente empregado, em 1919, em defesa do nacionalismo, e em contrariedade ao socialismo, sob a forma de um movimento chamado Fasci Italiani di Combattimento, desde o qual viria a derivar o Partido Nacional Fascista. Esse movimento não se caracterizava apenas pelo nacionalismo exacerbado, mas também por atos violentos de anti-intelectualismo e de ataques a propriedades burguesas.

Embora o movimento fascista tenha recebido seu nome na Itália, não foi apenas naquele país que se fomentaram organizações coordenadas por objetivos similares de nacionalismo e atos de violência. O exemplo da proliferação do fascismo na Europa tem na Alemanha nazista o extremo da aplicação do ódio que rege a existência desse movimento. Ao alinhar o nazismo como um movimento fascista é possível observar alguns critérios de similaridade, mas não estabelecer uma equivalência entre os diversos movimentos fascistas 
que proliferaram pela Europa e por outros continentes naquele momento da história da civilização. Embora os movimentos tenham variadas formas, a exaltação ao ódio e a violência são fatores que coletivizaram estadistas, empresários, artistas e demais membros da sociedade. Outro fator crucial a ser considerado é a personificação de um líder e a possibilidade de sua sustentação no poder. A edificação do líder fascista e sua manutenção no poder, inclusive por vias eleitorais, não pode ser desarticulada das massas e das instituições que promovem tais conjunturas.

O fascismo não toma um sistema filosófico como sua base, a qual se localiza no sentimento de superioridade compartilhado pela multidão, a atualidade da injustiça de suas condições e o direito de predominância sobre o outro que é julgado como inferior. É assim que, segundo Paxton (2007), "o fascismo não repousava na verdade de sua doutrina, mas na união mística do líder com o destino histórico de seu povo, ideia essa relacionada às ideias românticas de florescimento histórico nacional e de gênio individual artístico e espiritual" (p. 39). Essa união mística do líder com o nacionalismo, e o caráter ficcional que engendra essa aliança, deve ser considerada em relação ao fato de que os movimentos fascistas expressam uma particularidade cultural própria aos contextos nos quais se fazem surgir.

Ainda quando às particularidades desses movimentos, a figura fabricada de um inimigo também traz em seu bojo a marca de determinada cultura. O inimigo povoa a imaginação fascista, seja ele interno ou externo aos limites geográficos da nação. O momento histórico que se segue ao desfecho da Primeira Guerra Mundial tem no avanço do bolchevismo uma exacerbação das preocupações fronteiriças e uma propagação da aversão às minorias étnicas da Europa Ocidental. A ideia de um Estado nacional homogêneo é imperativa na definição de inimigo dos movimentos fascistas da Europa entre guerras. Certa justificativa fundada em um biologicismo que reconhece nos mecanismos de contágio e de hereditariedade os marcadores da delimitação de uma imagem. Se o inimigo é uma imagem, "cada cultura especifica seu próprio inimigo nacional" (Paxton, 2007, p. 72) e, dessa maneira, a Europa definiu na figura do judeu, do cigano, do eslavo etc. aquele que era perseguido.

A mesma justificativa biologicista que define o inimigo também foi utilizada, no exemplo extremo da política fascista, com a finalidade de extermínio. Os programas de eutanásia médica da Alemanha nazista foram voltados às minorias étnicas, aos subversivos e, também, aos portadores de doenças e aos loucos. Sobre a radicalização do fascismo em um regime totalitário, Arendt (1951/2012) afirma que não se procura “o domínio despótico dos 


\section{ARTIGOS}

homens, mas sim um sistema em que os homens sejam supérfluos. O poder total só pode ser conseguido e conservado em um mundo de reflexos condicionados, de marionetes sem o mais leve traço de espontaneidade" (p. 605). A redução do humano a uma categoria inassimilável é um projeto intrínseco à história do fascismo e executado pelos regimes totalitários em nome de um sistema que torna a vida supérflua. Sob as coordenadas da destrutividade que historicamente se coloca em prática nos projetos fascistas, a imagem do inimigo é constituída como índice de um repertório oriundo da primazia da raça, da nação e da família como sustentáculos da virtude e da superioridade. Tem-se, assim, que os temas dos movimentos se orientam por problemáticas culturais capazes de mobilizar massas em nome desse repertório sobre o qual se respalda o fascismo.

Tal como a imagem do inimigo é construída, o líder é também projetado pela propaganda fascista enquanto figura única de poder. Sendo esse um objetivo publicitário, um regime instalado se orienta apenas por esse aporte. É preciso considerar que a manutenção de um regime fascista tem nas instituições e nas alianças de cunho conservador um pilar político e social. É sobre essa arquitetura que se ergue a liderança do movimento e do regime fascista: trata-se de uma supremacia distinta de outros modelos de regimes conservadores e ditatoriais. É nesse ponto que se legitima o carisma do soberano como algo que transcende as mediações e que se baseia na "reivindicação de um status único e místico, colocando o líder como a encarnação da vontade do povo e o portador do destino desse povo" (Paxton, 2007, p. 209). O elo que liga o líder à massa encarna a vontade desta e se sobrepõe ao modelo de Estado em que a opinião pública é alcançada por vias democráticas. A relação entre o líder e seu público se difunde pela via da autoridade e isso não significa que exista coação entre as partes vinculadas. A massa não se opõe à violência e à política de terror dos regimes fascistas.

A subordinação ao poder do regime fascista é uma das características do Estado no qual não há autonomia dos direitos individuais. A suspensão do estado de direito viabiliza o projeto gestado pelo movimento fascista de criação de um novo homem e de uma nova mulher, de acordo com o que cada um guarda de particularidades, que se qualifiquem como vigorosos e subservientes. Os regimes fascistas se associam às coordenadas conservadoras não em prol do avanço econômico e social, e sim da guerra. É na guerra que se observou a radicalização embrionária nos movimentos fascistas, levada ao extremo pela Alemanha nazista e que configura o índice de um fim intrínseco ao fascismo: sua autodestruição (Paxton, 2007). Assim, ainda tendo o 
exemplo alemão em vista, a radicalização leva o movimento fascista a negar a própria nação em nome da destruição.

Com esse apanhado histórico é possível destacar que há dois estágios do fascismo marcados, primeiramente, pelo movimento e, em um segundo momento, pela ascensão ao poder. É no meandro dessa temporalidade que se delimita uma preocupação característica com a decadência e a humilhação de um determinado grupo que, em contrapartida, passa a compor:

cultos compensatórios da unidade, da energia e da pureza, nas quais um partido de base popular formado por militantes nacionalistas engajados, operando em cooperação desconfortável, mas eficaz com as elites tradicionais, repudia as liberdades democráticas e passa a perseguir objetivos de limpeza étnica e expansão externa por meio de uma violência redentora e sem estar submetido a restrições éticas ou legais de qualquer natureza. (Paxton, 2007, p. 359)

Não é nosso objetivo estabelecer uma exegese histórica dos fascismos enquanto movimento, partido e regime. Destaquemos que o fascismo é divergente dos paradigmas políticos do século XIX: liberalismo, conservadorismo e socialismo e que sua caracterização passa pela construção do ideário coletivo que apregoa unidade e purificação como objetivos que se sobrepõem aos projetos democráticos. A divergência dos paradigmas políticos vigentes abarca a proposta de que o fascismo se constitui de acordo com determinada época, com traços de um momento histórico e sem a necessidade de uma retomada minuciosa de suas faces relegadas ao passado europeu. Obviamente não se advoga aqui pelo apagamento da história, é preciso considerar, a partir de uma dialética entre a atualidade e o passado, que o fascismo "é um tipo particular de projeto conservador de organização da vida social dentro dos marcos da sociedade burguesa, fortemente ligado aos momentos de crise no seio do capitalismo no país ou região em questão" (Poggi, 2012, p. 11).

Acompanhando a proposta dos historiadores, o fascismo como movimento ou regime carrega em seu bojo o ensejo da radicalização pautada na coletivização de um projeto que idealiza família, nação e raça. Essa idealização projeta no líder a encarnação daquilo que é mais íntimo e que move a massa, isso se desenrola em um momento histórico marcado pela crise do sistema capitalista e pela predominância conservadora, sob a égide de um projeto que incide sobre a sociedade. A partir disso, interrogamos o lugar do fascismo em uma oposição ao laço social na medida em que seu status de projeto se concebe como uma propaganda da unidade que anularia o mal-estar. O fascismo, segundo nossa hipótese, pode ser caracterizado como 


\section{ARTIGOS}

um além do mal-estar próprio ao laço social configurado por um encontro místico com certo gozo que, como apontaremos, pode ser articulado pela ausência de laço social pela via do Discurso Capitalista.

\section{Entre Reich e Adorno: a proposta freudiana sobre o fascismo}

Freud (1921/1996a) interroga sobre a formação das multidões articulando tal organização a propostas a respeito da coesão da coletividade e aos fundamentos da constituição da família. Sua pesquisa recupera a descrição da mente coletiva, feita especialmente por Le Bon (1895/2018), que examina essa formação a partir da reunião de pessoas em unidades. Assim como um corpo formado por partes menores, a alma das multidões formadas por indivíduos diversos obedece a certa lei da unidade mental (p. 29) pautada em um contágio entre os elementos componentes. Esse contágio, que possui características hipnóticas, torna a multidão crédula e influenciável, dotada de sentimentos simplórios, exagerados e inclinados ao extremo. Um condutor, segundo essa perspectiva, pode ocupar certa posição privilegiada como nos rebanhos há uma tendência inata.

A importância da proposta de Le Bon (1895/2018) sobre a coesão das multidões é reconhecida por Freud (1921/1996a) que, ao mesmo tempo, critica a problemática localização do condutor enquanto um líder. Por via dessa crítica, o psicanalista inclui a sugestão e a libido como componentes essenciais na constituição das massas. $\mathrm{O}$ exame estabelecido por Freud nos orienta na articulação acerca do fascismo ao tomar como ponto de partida constatações sobre alterações mentais na sujeição do indivíduo à multidão. Assim, supor haver intensificação e extremização das emoções, em conjunto com a redução da capacidade intelectual e da racionalidade, são engrenagens do funcionamento das multidões que indicam a Freud a centralidade da libido como magnitude que promove a coesão.

Propor a libido como item central é incluir na constituição da multidão uma localização para aquilo que é do âmbito do erótico. A formação em questão é mantida em sua consistência pela libido ao intensificar os laços identificatórios entre os elementos, e os tornar vulneráveis à sugestão exercida nesse ambiente em nome da harmonia e da unidade. Esse funcionamento é proposto por Freud para pensar o vínculo libidinal entre os membros da Igreja e do Exército, grupos artificiais coesos em torno de uma liderança à qual se supõe amar de modo equivalente cada componente. $\mathrm{O}$ amor igualitário do 
líder é preconizado por Freud como o amor do pai pelos filhos, sendo essa a estrutura libidinal da multidão e que pode ser entendida em dois formatos: o laço com o líder e aquele entre os membros do grupo.

Enquanto o vínculo entre os elementos da multidão é pesado por intermédio da conceituação freudiana de identificação (1921/1996a, p. 115), a ligação entre os componentes e o líder é indicada a partir do modelo da idealização. Reforçando que o processo seja sustentado libidinalmente, a idealização requer que o objeto seja localizado enquanto ideal do eu em um estado de ser amado. Esse estado que se caracteriza pelo fascínio e pela servidão (Freud, 1921/1996a, p. 123) pode ser compreendido em contrariedade à identificação na medida em que o eu se empobrece em nome de seu estado de apaixonamento; já na identificação, há o enriquecimento do eu que introjeta o objeto. Essa distinção é apenas dinâmica, pois por uma via econômica e topográfica - de acordo com a metapsicologia freudiana — não há distinção visto haver uma supremacia do objeto sobre o eu.

A posição subjugada do eu em seu apaixonamento pelo líder é comparado ao estado de hipnose, já que "o hipnotizador constitui o único objeto e não se presta atenção a mais ninguém que não seja ele" (Freud, 1921/1996a, p. 124). Segundo o argumento freudiano, o desvio dos objetivos pulsionais contribui para a purificação de um fenômeno de devoção ilimitada que tem na hipnose um paradigma a ser aplicado em larga escala às grandes massas. A idealização do líder e a identificação entre os membros não deixa de ser articulada por Freud a partir da horda primeva, na qual o pai é o ícone erigido ao ideal a ser temido e amado, e os irmãos são os semelhantes, mutuamente amados e protegidos em uma estrutura que se sustenta pelo caráter erótico dos vínculos. Esse protótipo será pensado por dois autores que tomarão o texto freudiano como esteio de proposições sobre o movimento fascista.

O investimento libidinal, crucial na constituição do vínculo familiar, é indispensável na manutenção da multidão em sua coesão de elementos e na instituição do líder como ideal comum. Esse será o fundamento sustentado por Wilhelm Reich, em 1933/1988, em seu argumento sobre o fascismo como atitude mística e mecanicista do oprimido pela civilização autoritária. Reich (1933/1988) questiona sobre a motivação da constituição de uma liderança, tal qual Hitler naquele momento da história da Europa, oposta aos interesses dos trabalhadores. Sobre esse setor da sociedade que sobrevive do próprio trabalho, o autor localiza a problemática do fascismo como derivada do impasse no processo democrático frente ao qual são enaltecidos o misticismo e o culto à família autoritária. Nesse processo, a "identificação com a 


\section{ARTIGOS}

autoridade" (p. 43) é um fenômeno que demonstra como membros de uma determinada camada social podem se equivaler em atitudes e pensamentos, segundo Reich, às caricaturas da classe dominante, à nação e ao próprio Estado. Para além da miséria e do efeito patético apontados pelo autor no fenômeno, subjaz o posicionamento da família como valioso instrumento de poder: "é precisamente na situação familiar que encontramos a chave para o fundamento emocional da estrutura que descrevemos" (p. 43).

Sobre a família como instrumento de poder, Reich destaca a posição política e econômica do pai como estratégica para o Estado autoritário. Esse é o elo entre o Estado e a família, a reprodução da autoridade e da submissão desse contexto é alinhada pelo autor à localização do führer na Alemanha nazista. Assim, a posição do pai impõe à mãe e aos filhos rigorosas limitações sexuais cujo desdobramento tem na identificação ao líder um destino possível. A inibição e a fragilização da sexualidade são mantidas como alicerce pela família autoritária, que também encontra na religião o sustentáculo para o sentimento de culpa e que é mantida pelo Estado autoritário como princípio básico digno de ser protegido contra a desfaçatez dos inimigos.

A família como modelo para a ideologia fascista da organização hierárquica do Estado é uma "nação em miniatura" (Reich, 1933/1988, p. 57), é nela que cada membro se identifica com a nação enquanto construção idealizada. O führer, um mito, como personificação da nação encarna o sentimento da multidão com sendo um pai autoritário a partir da perspectiva da criança. É possível caracterizar nessa engrenagem a identificação ao próprio mito que, segundo o autor, é equivalente ao sentimento de desemparo do membro da massa que espera proteção e que passa a defender a herança nacional enquanto representante da superioridade. É assim que o fascismo "promete a abolição das classes, isto é, a abolição da condição de proletário" (p. 64), já que seus membros se igualam em torno da superioridade ideológica à qual se elevam nação e raça.

A respeito da raça é preciso considerar a mesma suposição de superioridade, que não se sustenta cientificamente, embora leve em conta um arcabouço biológico para teorizar o acasalamento das espécies como lei básica. Essa suposição se contrapõe à ideia de miscigenação a partir de um argumento sobre o declínio progressivo da raça e da necessidade de manutenção da superioridade compartilhada entre os membros identificados ao ideal de nação, raça e família. Em direção ao ideal de pureza determinada pelo autoritarismo e pelo patriarcado é que, propõe Reich (1933/1988), se sustenta o recalcamento e o medo da sexualidade. A pureza sexual é um 
distanciamento, um evitamento da corrosão dos laços familiares. Assim se edifica a "moral antissexual" (p. 88) defendida pela família autoritária como o baluarte e garantia da imunização contra o que provém do que é inferior e inimigo, a própria sexualidade.

Socialmente a família não é a base do Estado autoritário, é uma instituição de apoio político e econômico orientada no sentido de preservá-lo. Para Reich (1933/1988), o Estado autoritário é entendido pelas classes menos privilegiadas como um "todo orgânico" (p. 101) em uma perspectiva que condena a sexualidade e, ao mesmo tempo, exalta o autoritarismo em sua pureza. Essa exaltação compõe um propósito político que é examinado por Adorno (1951/2015), também em articulação ao texto freudiano (1921/1996a), em um questionamento a respeito da abolição da democracia pela massa que se compõe a partir do princípio democrático.

Adorno (1951/2015) ressalta a importância do que Freud (1921/1996a) havia antecipado a respeito do movimento de massa fascista sem sustentar um declarado interesse pela dimensão política, mas sim por um fenômeno social que se articula aos desenvolvimentos conceituais e teóricos da pesquisa psicanalítica. Questionar sobre como a formação das massas interferem na racionalidade e na transformação de características individuais é o que permite a Freud (1921/1996a), como já indicamos, problematizar a libido em sua centralidade na coesão e manutenção do elo. Por via desse esforço freudiano, Adorno enxerga a oportunidade de pensar a figura do "demagogo fascista" (p. 159) como aquele que tenta produzir sinteticamente um princípio unificador da multidão com o auxílio de dispositivos voltados às massas.

A atualidade do uso das mídias e redes sociais compartilha com o pretérito uso da propaganda o mesmo objetivo massificador. A contribuição de Adorno (1951/2015) se insere nessa problemática que teve na Alemanha nazista um exponencial histórico quanto ao uso da propaganda. A proposta freudiana é empregada a partir de seu principal fundamento, a vinculação libidinal e a suscetibilidade dos membros da multidão à sugestão, na elaboração do argumento segundo o qual o demagogo produz sinteticamente o vínculo entre os membros e destes com o líder. A técnica do demagogo equivale à do hipnotizador no direcionamento que reduz a um mero membro da massa.

É preciso sublinhar, na contribuição de Adorno (1951/2015), o caráter sintético daquilo que o demagogo fascista gera na formação e coesão da multidão. Isso é sintético visto não considerar a percepção ou a inteligência como variáveis; trata-se somente de um vínculo que se sustenta 


\section{ARTIGOS}

libidinalmente. Isso é determinante da propaganda fascista e da sustentação do líder enquanto uma ideia. Não importa se o líder é hábil e adequado ao projeto do cargo que ocupa, seu aporte é mantido apenas pela imagem que reanima o pai da horda em sua primitividade e ameaça. A construção da imagem de um "pequeno grande homem" (Adorno, 1951/2015, p. 172) é uma estratégia fascista na criação do líder como alguém que é parte do povo, viril e desprovido de riqueza material e espiritual. A obediência ao líder não o desconsidera como supérfluo, apenas há uma reconciliação dessa contradição ao se estabelecer a identificação com o opressor.

A propaganda fascista busca reproduzir padrões daquilo em que é altamente arraigada: na ignorância. A prevalência da ignorância encontra na dinâmica libidinal o cerne da manipulação aplicada em técnicas preestabelecidas desde interesses econômicos e políticos. Nisso se ampara a asserção de Adorno (1951/2015, p. 185) segundo a qual o fascismo não é propriamente um problema psicológico, já que estratégias de manipulação são amplamente elaboradas tendo em conta a suscetibilidade potencial das massas. A respeito desse mecanismo, Adorno (1951/2015) afirma:

Nesses átomos sociais [coletivos fascistas], as dinâmicas psicológicas de formação de grupo excederam a si mesmas e não são mais uma realidade. A categoria de "falsidade" (phonyness) aplica-se tanto aos líderes quanto ao ato de identificação por parte das massas e seu suposto frenesi e histeria. As pessoas acreditam tão pouco, do fundo de seu coração, que os judeus são o demônio, quanto acreditam completamente em seu líder. Elas não se identificam realmente com ele, mas representam (act) essa identificação, encenam (perform) seu próprio entusiasmo, e assim participam na encenação (performance) de seu líder. (p. 188)

O caráter sintético e a falsidade são categorias que permeiam os vínculos libidinalmente estabelecidos entre os membros da multidão e destes com o seu líder. O que é falso se torna preponderante nessa dinâmica que pode ser muito bem ilustrada, no Brasil atual, pela veiculação de informações falsas, fake news. O ensejo para questionar a atividade do demagogo fascista deve levar em consideração o fascínio pela performance em torno do falso. A encenação fascista é articulável ao que Reich (1933/1988) aponta sobre a família autoritária, sua localização estratégica enquanto nação mínima e a defesa de pressupostos sobre a raça. A superioridade historicamente conclamada pelos movimentos fascistas perpassa as categorias de raça, nação e família também como uma suposição que sinteticamente deriva do saber científico. O caráter sintético do conteúdo da manipulação fascista aponta o ideal de pureza e a 
consequente imunização contra aquilo que parece se aglutinar sob a forma do inimigo, mas que é o indício do mais próprio e íntimo a ser evitado. Questionaremos, a partir do próximo tópico, se isso que falsamente é predominante na manutenção do vínculo da multidão fascista pode ser compreendido como um objeto de consumo.

\section{O Discurso do Capitalista e seu objeto sintético}

A proposta freudiana (1930[1929]/1996b) de que os progressos de uma cultura envolvem certo preço a ser pago, indica a subtração daquilo que, como um a mais, comporia o programa da felicidade. As restrições ao campo pulsional situam o mal-estar como fundante da cultura que, desde então, contém em seu meandro a fonte de sofrimento originária das relações sociais, já que a mutualidade se sustenta em dada impossibilidade.

A insuficiência dos arranjos sociais é premente ao sofrimento derivado da renúncia pulsional. O relacionamento mútuo em sociedade não garante a retomada da perda que caracteriza a insuficiência, pelo contrário, sua constituição é reveladora de um impossível que Freud (1937/1996c) calca com categorias: governar, educar e analisar.

O impossível que sustenta o mal-estar na mutualidade em sociedade é radical no desdobramento que Lacan (1969-1970/1992) introduz a respeito dos discursos. Tomando como premissa da estruturação do inconsciente como linguagem, o discurso opera a partir do laço social e da perda nisso implícita. É do ordenamento entre significante-mestre $\left(\mathrm{S}_{1}\right)$ e saber $\left(\mathrm{S}_{2}\right)$, aparelho a partir do qual o sujeito (\$) é efeito e o objeto $a$ é causa, que o discurso articula linguagem e gozo. Os discursos são ordenamentos do laço social que operam pela movimentação dos quatro elementos destacados $\left(\mathrm{S}_{1}, \mathrm{~S}_{2}\right.$, S e $\left.a\right)$ por quatro lugares distintos (Agente, Outro, Produção e Verdade). O giro dos elementos sobre os lugares fixos permite a definição dos quatro discursos em torno do que se formaliza enquanto laço social pelo ordenamento vetorial do quadrante. $\mathrm{O}$ vetor que parte do lugar de Agente em direção ao Outro é proposto como o impossível da relação que se estabelece em cada discurso. Esta impossibilidade remete aos ofícios indicados por Freud (1937/1996c), alinhando governar, educar e analisar aos discursos: do mestre, da universidade e da psicanálise. Lacan (1969-1970/1992, p. 183) propõe o "fazer desejar" em relação ao discurso da histérica e articula as quatro estruturas discursivas de maneira não excludente. 
Discurso do Mestre

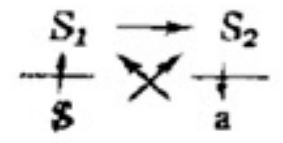

Discurso da Histérica

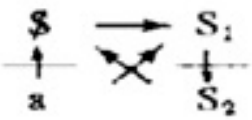

Discurso da Universidade

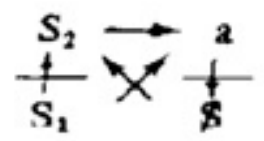

Discurso do Analista

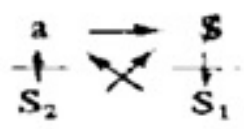

Discurso do Capitalista

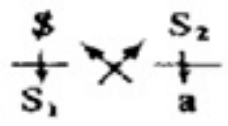

A renúncia pulsional fundamentada pela proposta freudiana de um mal-estar (1930[1929]/1996b) é o que estabelece o laço social, ou seja, é pela perda no campo do gozo, pela entropia em que um excesso se perde, que os discursos se estruturam enquanto "aparelho de gozo" (Lacan, 1969-1970/1992, p. 50). De forma privilegiada, o discurso do mestre demonstra o funcionamento da lógica significante, em um encadeamento no qual o objeto $a$ é o produto e o sujeito é efeito que ocupa o lugar da verdade. É nesse lugar que o sujeito permanece obturado em uma finalidade de supressão da castração e redução ao $\mathrm{S}_{1}$. A identificação de $\$$ com $\mathrm{S}_{1}$ acontece na medida em que o mestre desconhece o que lhe falta e consome aquilo que se produz a partir de um saber sem sujeito. Esse usufruto por parte do mestre é uma homologia entre a mais-valia marxista e a proposta lacaniana de um mais gozar.

A partir dessa homologia se engendra um Discurso Capitalista, desde o qual se diferencia um mestre antigo de outro moderno, o capitalista. Pela mais-valia enquanto excedente da incongruência entre o valor de uso e o valor de troca da força de trabalho e pela denúncia de espoliação que se promove por 
esse mecanismo, entende-se que o mais gozar, enquanto mercadoria ofertada pelo capitalismo industrial, revela um gozo que não envereda à perda, mas que é disponibilizado como gadget. Sobre isso, afirma Lacan (1970/2003):

A mais-valia é a causa do desejo do qual uma economia faz seu princípio: o da produção extensiva, portanto insaciável da falta-de-gozar (manque-à-jouir). Esta se acumula, por um lado, para aumentar os meios dessa produção como capital. Por outro lado, amplia o consumo, sem o qual essa produção seria inútil, justamente por sua inépcia para proporcionar um gozo com que possa tornar-se mais lenta. (p. 434)

Há uma mutação que diferencia o Discurso do Mestre antigo, cujo mandamento é ordenativo e soberano na criação de direitos e deveres, e o Discurso Capitalista como um novo mestre que condiciona o gozo. De acordo com a disposição dos elementos proposta por Lacan (1972/1978), o saber $\left(\mathrm{S}_{2}\right)$ está reduzido ao trabalho com vistas à produção do mais gozar em forma de objeto de gozo para o sujeito consumidor. Há nisso um alinhamento à tecnicização da ciência e aos desbobramentos viabilizados pelo Discurso Universitário. Em uma torção, o sujeito torna-se agente do consumo ordenado pela disponibilidade do objeto produzido. É desse lugar de pseudodominação que o sujeito ávido consome desenfreadamente os objetos forjados para tais fins. De acordo com Lacan (1972/1978):

Freneticamente astucioso, mas condenado a ser furado.

Isto que é insustentável, algo que eu poderia lhes explicar, pois o discurso do capitalista está lá, vocês o veem com uma pequena inversão apenas entre o $\mathrm{S}_{1} \mathrm{e}$ o \$ que é o sujeito. É o suficiente para que isto funcione como uma roleta. Isto não poderia ter melhor funcionamento e, por isso, funciona muito rápido. Isto se consome, é consumido enquanto se consuma. (p. 51)

Esses objetos compõem uma gama de apetrechos e bugigangas tecnológicas e, como propomos, sua estrutura coincide como aquela apregoada de caráter sintético que mantém coesa a massa fascista. O Discurso Capitalista consegue manter um circuito fechado em que o sujeito é gerido pelo objeto de gozo em acordo aos meandros que coordenam o consumo. Esse discurso é frenético e astucioso e, segundo Lacan (1972/1978), se consuma na medida em que consome. Nele, o objeto incumbido na função de mais-gozar faz funcionar uma economia que gere o sujeito ávido em que um falso encontro com certo gozo. Dessa maneira, estabelece-se, na ausência de laço social, a relação do sujeito com o gadget em ordenamento à falta de gozo. É, assim, questionável a essência de discurso desse que não apresenta um agente que se 


\section{ARTIGOS}

dirige ao outro e que não compõe um quinto, mas uma derivação que mantém a ordenação de $\mathrm{S}_{1}$, ora no lugar da verdade. O lugar de agente ocupado pelo sujeito não se veicula ao outro, $\mathrm{S}_{2}$, que, por sua vez, opera pela tecnicização da ciência em um ordenamento oriundo do lugar da verdade.

O sujeito do Discurso Capitalista faz semblante do mestre que o manipula desde o lugar de verdade. Essa manipulação distancia o sujeito do saber e o implica, enquanto instância egoica, em um profundo desconhecimento de sua divisão. Essa obturação é favorecida pelo encontro com o objeto sinteticamente forjado em nome de um ideal de pureza e de imunização contra aquilo que é projetado no inimigo, mas que remete ao mais próprio e evitável de si: a falta.

\section{Considerações finais}

A fabricação da notícia, a propagação da desinformação e a inconclusividade sobre os fatos encontram nas redes sociais um terreno bastante fértil em que a propagação e o alcance são de eficácia perceptível. As fake news mobilizam um grande público que se divide entre apoiadores, testemunhas e opositores e, segundo Dalmazo e Valente (2018), "a ampliação do consumo de notícias por sites de redes sociais também fomenta um novo tipo de concorrência com mídias tradicionais. As fake news se assentam também na crise de confiança dos leitores nos veículos tradicionais" (p. 159). A propagação e o alcance desses objetos fabricados se apoiam na capacidade de julgamento forjada pela própria notícia. Há concorrência com os veículos de comunicação que, quando não são disseminadores das mesmas fontes obtusas, contam com descredibilidade e persecutoriedade das massas animadas pelos conteúdos ostensivamente disparados.

O caráter sintético que compõe as fake news encontra na manipulação promovida pela figura do demagogo fascista, de Adorno (1951/2015), a mais precisa descrição cuja desconsideração da percepção e da inteligência é crucial na sustentação coesa da multidão fascista. Essa manipulação se orienta pelos ideais de pureza sexual e na edificação da moral que garante imunidade frente ao que se lança como imagem do inimigo. Essa rejeição ao outro, que deve ser eliminado, remete, de acordo com Reich (1933/1988), ao mais íntimo da própria sexualidade. Tanto o caráter sintético quanto a abominação ao sexual se combinam em um objeto que implica o sujeito e que produz um velamento da falta. 
Sobre esse velamento, é preciso considerar que a estrutura fantasmática $(\$ \diamond$ a) comporta a relação do sujeito barrado com o objeto $a$, e a obturação disso é preponderante em uma política do Discurso Capitalista. O sujeito, a partir da obturação da estrutura fantasmática se confunde com a instância egoica em uma profunda recusa da ausência daquilo que não é unitário. $\mathrm{O}$ encontro com esse objeto forjado pelo saber demagógico tem como favorável o líder que, desde a posição de verdade, rege o sujeito em seu semblante de mestre. Trata-se de um a mais de gozo que, enquanto objeto enigmático e gerador de fascínio, demarca o ilimitado próprio ao capitalismo.

Justapor os elementos do Discurso Capitalista em um ordenamento que conjuga o líder, o saber demagógico, o objeto sintético forjado e o sujeito em sua recusa à dimensão da falta é o que permite articular esse discurso sem laço ao que temos destacado a respeito da coesão da multidão fascista. Essa coesão se promove pelo consumo do objeto falacioso e reafirma a eminência, destacada por Freud (1921/1996a), da libido como peça-chave na montagem fascista.

\section{Referências}

Adorno, T. W. (2015). A teoria freudiana e o padrão de propaganda fascista. In T. W. Adorno, Ensaios sobre psicologia social e psicanálise. São Paulo, SP: Editora Unesp. (Trabalho original publicado em 1951).

Arendt, H. (2012). Origens do totalitarismo. São Paulo, SP: Companhia das Letras. (Trabalho original publicado em 1951).

Delmazo, C., \& Valente, J. C.L. (2018). Fake news nas redes sociais online: propagação e reações à desinformação em busca de cliques. Media \& Jornalismo, 18(32), 155-169. Recuperado em maio 2020 de: <http://www.scielo. mec.pt/scielo.php?script=sci_arttext\&pid=S2183-54622018000100012\&lng=pt $\&$ tlng $=\mathrm{pt}>$.

Freud, S. (1996a). Psicologia de grupo e a análise do ego. In Edição Standard Brasileira das Obras Psicológicas Completas de Sigmund Freud. (J. Salomão, trad.; Vol. 18, pp. 79-154). Rio de Janeiro, RJ: Imago. (Trabalho original publicado em 1921).

Freud, S. (1996b). Mal-estar na civilização. In Edição Standard Brasileira das Obras Psicológicas Completas de Sigmund Freud. (J. Salomão, trad.; Vol. 21, pp. 67148). Rio de Janeiro, RJ: Imago. (Trabalho original publicado em 1930 [1929]).

Freud, S. (1996c). Análise terminável e interminável. In Edição Standard Brasileira das Obras Psicológicas Completas de Sigmund Freud. (J. Salomão, trad.; Vol. 23, 


\section{ARTIGOS}

pp. 225-270). Rio de Janeiro, RJ: Imago. (Trabalho original publicado em 1937).

Lacan, J. (1978). Discours de Jacques Lacan à l’Université de Milan, le 12 mai 1972. In Lacan in Italia. Milão, IT: La Salamandra. (Trabalho original publicado em 1972).

Lacan, J. (2003). Radiofonia. In Outros escritos (pp. 400-447). Rio de Janeiro, RJ: Jorge Zahar. (Trabalho original publicado em 1970).

Lacan, J. (1992). O seminário. Livro 17. O avesso da psicanálise. Rio de Janeiro, RJ: Jorge Zahar. (Trabalho original publicado em 1969-1970).

Lacan, J. (1998). O seminário. Livro 11. Os quatro conceitos fundamentais da psicanálise. Rio de Janeiro, RJ: Jorge Zahar. (Trabalho original publicado em 1964).

Lacan, J. (2009). O seminário. Livro 18. De um discurso que não fosse semblante. Rio de Janeiro, RJ: Jorge Zahar. (Trabalho original publicado em 1971).

Le Bon, G. (2018). Psicologia das multidões. São Paulo, SP: Martins Fontes. (Trabalho original publicado em 1895).

Paxton, R. O. (2007). A anatomia do fascismo. São Paulo, SP: Paz e Terra.

Poggi, T. (2012). Faces do extremo: uma análise do neofascismo nos Estados Unidos da América 1970-2010. Tese de doutorado apresentada ao Programa de Pós-graduação em História da Universidade Federal Fluminense. Recuperado em maio 2020 de: <https://www.historia.uff.br/stricto/teses/Tese-2012_Tatiana_Poggi. pdf $>$.

Reich, W. (1988). Psicologia de massas do fascismo. São Paulo, SP: Martins Fontes. (Trabalho original publicado em 1933).

\section{Resumos}

(Fascism and Capitalist Discourse: a synthetic object)

This article is based on two statements made by Lacan regarding fascism, and is guided by questioning the object value of fallacious elements, offered as promoters of cohesion in the fascist crowd, which spread and are quickly consumed. These objects allow a historical examination of the fascist ideal and an articulation with the Lacanian propositions on the Capitalist Discourse. Freudian contributions about the libidinal maintenance of the crowds are resumed, as well as their impact on the thought of Reich and Adorno in their assertions about fascism. Juxtaposing the elements of the Capitalist Discourse in an order that combines the leader, the demagogic knowledge, the forged synthetic object, and the subject refusing the 
dimension of the lack, allows to articulate this socially decoupled discourse to the highlights regarding the fascist crowd cohesion.

Key words: Psychoanalysis, capitalism, fascism, discourses

(Fascisme et Discours Capitaliste: un objet synthétique)

Cet article a pour point de départ deux déclarations de Lacan à propos du fascisme. Il est guidé par la remise en cause de la valeur des éléments fallacieux qui s'offrent comme agents de cohésion de la foule fasciste et qui se propagent et se consomment rapidement. Ces objets permettent de réaliser un examen historique de l'idéal fasciste et une mise en rapport avec les propositions lacaniennes sur le Discours Capitaliste. Les contributions freudiennes sur le maintien libidinal des foules sont reprises, ainsi que leur impact sur la pensée de Reich et d'Adorno dans leurs thèses sur le fascisme. La juxtaposition des éléments du Discours Capitaliste dans un ordre qui combine le leader, le savoir démagogique, l'objet synthétique forgé et le sujet dans son refus de la dimension du manque, c'est ce qui permet d'articuler ce discours sans lien social avec ce qui ressort de la cohésion de la foule fasciste.

Mots clés: Psychanalyse, capitalisme, fascisme, discours

(Fascismo y Discurso Capitalista: un objeto sintético)

Este artículo parte de dos declaraciones hechas por Lacan con respecto al fascismo, y se guía por el cuestionamiento del valor de objeto de los elementos falaces, que se ofrecen como promotores de la cohesión en la multitud fascista, que se propagan y se consumen rápidamente. Estos objetos permiten un examen histórico del ideal fascista y una articulación con las proposiciones lacanianas sobre el discurso capitalista. Se retoman las contribuciones freudianas sobre el mantenimiento libidinal de las multitudes, así como su impacto en el pensamiento de Reich y de Adorno en sus afirmaciones sobre el fascismo. Yuxtaponer los elementos del discurso capitalista dentro de un esquema que conecta al líder, al conocimiento demagógico, al objeto sintético forjado y al sujeto en su rechazo a la dimensión de la carencia es lo que permite articular este discurso sin lazo social a lo que destaca sobre la cohesión de la multitud fascista.

Palabras clave: Psicoanálisis, capitalismo, fascismo, discurso 


\section{ARTIGOS}

Citação/Citation: Brunhari, M. V. (2021, set.). Fascismo e Discurso Capitalista: um objeto sintético. Revista Latinoamericana de Psicopatologia Fundamental, 24(3), 597-617. http:// dx.doi.org/10.1590/1415-4714.2021v24n3p597.7.

Editora/Editor: Profa. Dra. Sonia Leite

Submetido/Submitted: 17.6.2020 / 6.17.2020 Aceito/Acepted: 26.12 .2020 / 12.26.2020

Copyright: (C) 2009 Associação Universitária de Pesquisa em Psicopatologia Fundamental/ University Association for Research in Fundamental Psychopathology. Este é um artigo de livre acesso, que permite uso irrestrito, distribuição e reprodução em qualquer meio, desde que o autor e a fonte sejam citados / This is an open-access article, which permits unrestricted use, distribution, and reproduction in any medium, provided the original authors and sources are credited.

Financiamento/Funding: Este trabalho não recebeu apoio. / This work received no funding.

Conflito de interesses/Conflict of interest: $\mathrm{O}$ autor declara que não há conflito de interesses. / The author declares that there is no conflict of interest.

\section{Marcos Vinicius Brunhari}

Professor Adjunto do Instituto de Psicologia e do Programa de Pós-Graduação em Psicanálise da Universidade do Estado do Rio de Janeiro - UERJ (Rio de Janeiro, RJ, Br.)

Rua São Francisco Xavier, 524 - Maracanã

20550-900 Rio de Janeiro, RJ, Br

mvbrunhari@gmail.com

https://orcid.org/0000-0002-5369-2915

This is an open-access article, which permits unrestricted use, distribution, the original authors and sources are credited. 